\title{
Physical Inactivity among Danish and Colombian Adolescents with Lower Level of Family Affluence
}

\author{
Patricia Olaya-Contreras ${ }^{1,2} \&$ Christiane Stock ${ }^{1}$ \\ ${ }^{1}$ Unit for Health Promotion Research, University of Southern Denmark, Esbjerg, Denmark \\ ${ }^{2}$ Department of Postgraduate Studies, Faculty of Nursing, University of Antioquia, Medellín, Colombia \\ Correspondence: Christiane Stock, Unit for Health Promotion Research, University of Southern Denmark, Niels \\ Bohrs Vej 9-10, 6700 Esbjerg, Demark. Tel: 45-6550-4210. E-mail: cstock@health.sdu.dk
}

$\begin{array}{lc}\text { Received: January 21, } 2016 & \text { Accepted: February 25, } 2016 \quad \text { Online Published: April 29, } 2016 \\ \text { doi:10.5539/gjhs.v8n12p104 } & \text { URL: http://dx.doi.org/10.5539/gjhs.v8n12p104 }\end{array}$

\begin{abstract}
Background \& Objectives: This study aimed to assess levels of physical activity (PA) and sedentary behaviours among Danish and Colombian adolescents, and to compare relevant environmental and psychosocial factors associated with physical inactivity (PI) between both student groups. Further, we aimed to compare PI between Danish students born in Denmark and those with immigrant background living in Denmark, but born in another country.
\end{abstract}

Methods: The comparative study was performed with 1.374 Danish adolescents (among them 152 born outside the country) who participated in the Danish Youth Cohort and 452 Colombian students who completed the ISCOLE questionnaire, both from the most disadvantaged socioeconomic strata.

Results: The prevalence of physical inactivity (PI) was much higher among Colombian students (74.6\%) compared with Danish (25.2\%) and with students with a non-Danish background living in Denmark (21.1\%). Both groups of Danish adolescents participated more often in organized sports, spent more time on sports after school, were more likely to actively commute to school compared to Colombians and spent less time on screen viewing than Colombians did. In both Columbian and Danish students, low time spent on sports after school, and poorer self-perceived health, were associated with PI. Sedentary behaviours (time in front of screen) were also positively associated with PI.

Conclusion: Most Colombian adolescents were not meeting the recommendation of accumulating at least 60 minutes per day of moderate-to-vigorous intensity PA for positive health outcomes as most Danish adolescents did independently of their ethnic background. We assume that the physical and social environment in the neighbourhoods where adolescents live may explain the differences in levels of PA between the countries.

Keywords: physical activity, ethnicity, family affluence, sedentary behaviour

\section{Introduction}

Worldwide it has been stated that an important amount of overweight and obesity could be avoided through physical activity (PA) and improved dietary behaviour (Gruber \& Haldeman, 2009; Hardy, King, Espinel, Cosgrove, \& Bauman, 2010; Lawman \& Wilson, 2012; Aballay, Eynard, Díaz, Navarro, \& Muñoz, 2013, World Health Organization [WHO], 2014). Nevertheless, young people commonly remain physically inactive and spend the majority of their discretionary time engaging in sedentary pursuits (Espinel; Laws, Bonfiglioli, Hardy, \& King, 2013; Colley, Garriguet, Janssen, Craig, Clarke, \& Tremblay, 2011; Hamrani, Mehdad, El Kari, El Hamdouchi, El Menchawy, Belghiti, El Mzibri, Musaiger, Al-Hazzaa, Hill, Mokhtar, \& Aguenaou, 2015). As one of the reasons, adolescents today have fewer opportunities to be active in a safe and independent manner, especially in large cities where rapid urbanization negatively affects the degree, extend and frequency of PA (Eyre, Duncan, Birch, Cox, \& Blackett, 2015). For instance, in Pelotas, Brazil, the prevalence of sedentary lifestyles characterized by excessive TV viewing and lack of PA among adolescents had a prevalence of more than 50\% (Azevedo, Menezes, Assunção, Gonçalves, Arumi, Horta, \& Hallal, 2014). North American children and adolescents spend between $40 \%$ and $60 \%$ of their waking hours engaging in sedentary activities (Saunders, Chaput, \& Tremblay, 2014). In Europe, levels of physical activity have significantly been decreased over the last years among both, 11 and 15 year old adolescents (Currie, Zanotti, Morgan, Currie, de Looze Roberts, Samdal, 
Smith, \& Barnekow, 2012). A recent study conducted in UK concluded that outdoor environments are important for health-enhancing PA and thus reducing obesity in deprived and ethnic minority children (Eyre et al., 2015). Moreover, in most of the countries boys continue to be significantly more active than girls are (Currie et al., 2012; Graham, Bauer, Friend, Barr-Anderson, \& Nuemark-Sztainer, 2014). Disparities in PA levels have also been described regarding differences between ethnic groups, e.g. between Black and White adolescents (Babey, Wolstein, \& Diamand, 2015) or between adolescents from urban and rural areas (Moore, Jilcott, Shores, Evenson, Brownson, \& Patterson, 2010). In Denmark, more children with lower social backgrounds are physically inactive than those eith higher ones (Henriksen, Rayce, Melkevik, Due, \& Holstein, 2015).

Lack of PA has severe consequences for the health of adolescents as the European Physical Activity Guidelines posit (European Commission, 2013). Excessive sedentary behaviours, i.e. TV-viewing or playin computer video games, have been found to be independently associated with adiposity and cardiometabolic risk factors (Saunders et al., 2014; Lawman \& Wilson, 2012). Moreover, among boys and girls with obesity commonly poor nutritional habits have been seen in association with screen-time (Marsh, Ni Mhurchu, Jiang, \& Maddison, 2014). In Scandinavia, in the last decades, there was an increase in the prevalence of obesity. For instance, in Denmark such an increase was described (Persson, Hansen, Sørensen, \& Baker, 2010) with a potential stagnation in the obesity epidemic among children between 2002 and 2007, but a still continuing increase among adolescents. In adolescent girls, the prevalence of obesity increased from $23 \%$ to $25 \%$ and in boys from $16 \%$ to $19 \%$ within five years (Persson et al., 2010). Similarly in Sweden, between 1999 and 2005 increased trends for obesity among 10-11 year old adolescents have been observed with a recently stabilizing obesity rate particularly in urban Sweden (Lissner, Sohlström, Sundblom, \& Sjoberg, 2010). In Sweden and the UK obesity and overweight are more common among adolescents from low socioeconomic environments (Lissner, Mehlig, Sjöberg, Chaplin, Niklasson, \& Albertsson-Wikland 2013; Eyre et al., 2015).

In Latin America, obesity rates have dramatically increased in the last decades (Abally et al., 2013). Particularly in Colombia, the prevalence of obesity in adolescents aged 6 to 11 years and adolescents aged 12 to 17 years has increased three-fold between 1980 and 2010 according to the National Survey on the Nutritional Situation (Instituto Colombiano de Bienestar Familiar, 2011). In Medellin, for children and adolescents under 18 years of age stunted growth (height for age) and overweight/obesity have been found as the two most critical problems with $12 \%$ of children under 10 years of age showing stunted growth and $5 \%$ presenting obesity (Salazar Jaramillo, Valencia Correa, Monsalve, Uribe Correa, \& Meíja Franco, 2010). The nutritional transition is characterized by modifications in diet and activity patterns that are directly determined by the socioeconomic and demographic changes of underdeveloped countries, which bring a high prevalence of poor nutrition and sedentary lifestyle in low-resource populations (Lawman \& Wilson, 2012; Aballay et al., 2013).

The physical and the social environment are central predictors for the level of PA in adolescents (Babey et al., 2015; Lawman \& Wilson, 2012). In many Latin American countries the lack of safe outdoor environments plays a key role in this transition. E.g. in Colombia urban violence results in conditions and environments not appropriate or safe to practice outdoors PA.

Physical inactivity continues to be a substantial concern calling for public health action. Cultural factors related to ethnic origin and societal trends such as urbanisation and environmental issues may contribute to the decrease of PA (Babey et al., 2015; Azevedo et al, 2014; Eyre et al., 2015; Saunders et al., 2014; Henrikson et al., 2015). Therefore, it is relevant to study the underlying factors associated with PA and sedentary behaviours by comparing adolescent populations with different ethnic and societal background in order to reveal the most important factors relevant for the prevention of increasing sedentary behaviours among youth, and in particular, among youth with low socioeconomic background. To our knowledge, such disparities affecting levels of PA in Latin-American adolescents compared to Scandinavian adolescents with low socioeconomic background have not yet been studied.

This study compares practices of PA and sedentary behaviour between adolescents with low socioeconomic background from Denmark and adolescents with low socioeconomic background from Medellín, Colombia. Furthermore, we study relevant environmental and psychosocial factors associated with physical inactivity among these students. In addition, we compare practices of PA and sedentary behaviour between Danish adolescents with Danish background and adolescents with non-Danish background.

\section{Method}

\subsection{Samples and Data Collections}

The sample from Denmark is a sub-sample of the baseline data of the Danish Youth Cohort (Ungeshverdag.dk) collected in the year 2005 that studied alcohol drinking among adolescents and addressed related health and 
lifestyle factors. The Danish Youth Cohort had a sample size of 12,498 (mean age: 13.4 years), representing $18.2 \%$ of the total population in the 7 th grade in schools in Denmark with a response rate of $63 \%$. For our analyses, we restricted the sample to students of 13-14 years of age and to those in the three lowest groups of socioeconomic level. The three-item family affluence scale (FAS) including number of cars in the household, number of holidays in the family within the last year, and ownership of own bedroom similar to Currie, Molcho, Boyce, Holstein, Torsheim and Richter (2008) was used as a measure of socioeconomic status of the family. The FAS score ranged from 0-5 and the sample was restricted to FAS 0-2. This resulted in a final sub-sample of the Danish Youth Cohort for our analysis of 1.374 adolescents. To study differences between Danish adolescents born in Denmark and adolescents with migrant background (non-Danish background) we used the questionnaire item: "In which country are you born?" and stratified the Danish sample into adolescents who answered "Denmark" ( $\mathrm{n}=1.222)$ and those who answered "In another country" $(\mathrm{n}=152)$

The sample from Colombia is a sub-sample of the baseline data of a main study that combined mixed methods to collect and analyse information regarding PA patterns, weight status, and obesity. The data collection took place in the year 2013. The detailed methodology of the study is described elsewhere (Olaya-Contreras, Bastidas, \& Arvidsson, 2014). The Colombian students were from the José Félix Restrepo Institute in Medellín, the largest public school in the Department of Antioquia with around 7000 students that represents the city's 16 communes (249 urban neighbourhoods and 5 rural subdivisions) and several municipalities of Antioquia. The majority of the students attending this school (92.7\%) came from the lowest socioeconomic strata 1,2, and 3, according to the Departamento Nacional de Planeación and the SISBEN categorization (Sistema de Identificación de Potenciales Beneficiarios de Programas Sociales). The student's SES is registered according to their parents' SISBEN classification, which needs to be supported by documents and receipts, i.e. electricity, a.m. A randomized stratified sampling was used to select study participants and the total sample was comprised of 654 students with a response rate of $81 \%$. For analyses, we restricted the sample to 13-14 year old students and to those from the 3 lowest socioeconomic strata (1-3), which resulted in a final sample of 426 students.

\subsection{Questionnaires}

The Danish questionnaire from the Danish Youth Cohort study contained information on adolescent lifestyle, and environments toward PA; domains of PA including transport to school, fitness and sports, sedentary behaviours, leisure time activities, family factors, school factors and background, as well as ethnicity, sex, and material wealth of the family (Vinther-Larsen, Riegels, Rod, Schiøtz, Curtis, \& Grønbaek, 2010).

The Colombian questionnaire (ISCOLE) covers lifestyles and environments toward PA, domains of PA including transport to school, fitness and sports, outdoor PA, and sedentary behaviours, and has been validated for children from low to high income countries across several regions of the world including Colombians (Katzmarzyk et al., 2013). The questionnaire was a compilation of validated items obtained from several different existing questionnaires or sources and new questions designed by ISCOLE investigators in the case that no suitable alternatives were found. In addition, multi-item scales from the ISCAPH-questionnaire obtained information on self-efficacy-and motivation to PA. Furthermore, some items from the Health-Related Quality of Life (HRQoL) scale, validated for Colombian adolescents were assessed through the KIDSCREEN-27 questionnaire (Ravens-Sieberer, Auquier, \& Erhard, 2007; Velez \& García, 2012). The items were physical and psychological well-being (self-perceived health) and school environment (perceived performance at school), which were compared to the respective questions in the Danish questionnaire (Table 1).

Table 1. Operationalization of the compared variables between the two samples from Denmark and Colombia

\begin{tabular}{|c|c|c|c|}
\hline $\begin{array}{l}\text { Variable } \\
\text { analysis }\end{array}$ & in the & $\begin{array}{l}\text { Item formulation in the Danish and Colombian } \\
\text { questionnaires }\end{array}$ & Operationalization \\
\hline \multirow{6}{*}{$\begin{array}{l}\text { Belonging } \\
\text { club/team }\end{array}$} & \multirow{6}{*}{ to sports } & Denmark: & \\
\hline & & Do you belong to a sport club (free time or youth club)? & Yes $=1$ \\
\hline & & $\begin{array}{l}\text { No, I do not go to any club, Yes, but not so much, Yes, } \\
\text { the majority of the days, } 1-2 \text { hours a week, Yes, the } \\
\text { majority of the days, } 3-4 \text { hours a week) }\end{array}$ & $\mathrm{No}=2$ \\
\hline & & Colombia & \multirow{3}{*}{$\begin{array}{l}\mathrm{Yes}=1 \\
\mathrm{No}=2\end{array}$} \\
\hline & & Do you belong to a sports team or club? & \\
\hline & & Yes, No & \\
\hline
\end{tabular}




\begin{tabular}{|c|c|c|}
\hline \multirow{3}{*}{$\begin{array}{lr}\text { Time spent } & \text { on } \\
\text { sports/exercise } & \text { after } \\
\text { school per week } & \end{array}$} & Denmark: & None \\
\hline & $\begin{array}{l}\text { How many hours per week do you usually exercise in } \\
\text { your free time? }\end{array}$ & $\begin{array}{l}\leq 1 \mathrm{~h}, \\
2-3 \mathrm{~h}\end{array}$ \\
\hline & (no exercise, $\leq 1 \mathrm{~h}, 2-3 \mathrm{~h},>4 \mathrm{~h}$ ) & $>4$ \\
\hline \multirow{11}{*}{$\begin{array}{l}\text { Time spent } \\
\text { TV/computer } \\
\text { (hours/day) }\end{array}$} & Colombia: & None \\
\hline & $\begin{array}{l}\text { Outside school hours: How many hours do you spend on } \\
\text { sports/exercise after School, per week? }\end{array}$ & $\begin{array}{l}\leq 1 \mathrm{~h} \\
2-3 \mathrm{~h}\end{array}$ \\
\hline & $(0,1,2,3,4,5,6,7,8,9,10$, hours $)$ & $\geq 4$ \\
\hline & Denmark: & None \\
\hline & About how many hours a day do you usually watch & $<=1 \mathrm{~h}$ \\
\hline & TV?, play games on a computer or games console? & $>1-4 h$ \\
\hline & (I do not watch/play, $<1 / 2 \mathrm{~h}, 1 / 2 \mathrm{~h}-1 \mathrm{~h}, 1-4 \mathrm{~h},>4 \mathrm{~h}$ ) & $>4 \mathrm{~h}$ \\
\hline & Colombia: & None \\
\hline & On a school day, how many hours did you watch TV? & $<=1 \mathrm{~h}$ \\
\hline & On a school day, how many hours did you play video or & $>1-4 h$ \\
\hline & $\begin{array}{l}\text { use computer for something that was not schoolwork? } \\
(<1 \mathrm{~h}, 1 \mathrm{~h}, 2 \mathrm{~h}, 3 \mathrm{~h}, 4 \mathrm{~h}, 5 \text { or more, continuous) }\end{array}$ & $>4 \mathrm{~h}$ \\
\hline \multirow{3}{*}{$\begin{array}{l}\text { Physical education } \\
\text { (PE) classes at school }\end{array}$} & Denmark: & $<2 \mathrm{~h}$ \\
\hline & $\begin{array}{l}\text { How many hours did you go to PE classes per week? } \\
(0,1,2,3,4,5 \text { hours/week continuous })\end{array}$ & $>2 \mathrm{~h}$ \\
\hline & Colombia: & \\
\hline \multirow{7}{*}{$\begin{array}{l}\text { Time on journey to } \\
\text { School }\end{array}$} & In the last week you were in school, on how many days & $\leq 2 \mathrm{~h}$ \\
\hline & $0,1,2,3,4,5$ days (ordinal) 1 day $=1$ hour & $32 \mathrm{n}$ \\
\hline & Denmark: & $<5 \mathrm{~min}$ \\
\hline & $\begin{array}{l}\text { How long did it take you to travel to school when you } \\
\text { walk, ride bicycle, roller-blade, skateboard, or scooter? }\end{array}$ & 5-15 min, 16-30 min, \\
\hline & $(<5 \min , 5-15 \min , 16-30 \mathrm{~min}, 31 \mathrm{~min}-1 \mathrm{~h},>1 \mathrm{~h})$ & $31 \min -1 \mathrm{~h},>1 \mathrm{~h}$ \\
\hline & Colombia: & $<5 \mathrm{~min}$ \\
\hline & $\begin{array}{l}\text { How long did it take you to travel to school? } \\
(<5 \mathrm{~min}, 5-15 \mathrm{~min}, 16-30 \mathrm{~min}, 31 \mathrm{~min}-1 \mathrm{~h},>1 \mathrm{~h})\end{array}$ & $\begin{array}{l}5-15 \min , 16-30 \min , \\
31 \min -1 \mathrm{~h},>1 \mathrm{~h}\end{array}$ \\
\hline \multirow{3}{*}{ Self-perceived health } & Denmark: & \\
\hline & Would you say your health is? & $2=$ Fair Poor \\
\hline & Excellent, good, fair, poor & \\
\hline \multirow{9}{*}{$\begin{array}{l}\text { Self-perceived } \\
\text { performance at school }\end{array}$} & Colombia: & $1=$ Excellent, Very good, \\
\hline & In general, how would do you say your health is? & Good \\
\hline & Excellent, very good, good, fair, poor & $2=$ Fair, Poor \\
\hline & Denmark: & $1=$ Verv Good $\mathrm{G}$ \\
\hline & How do you feel you are doing in school, academically? & $2=$ Average below average \\
\hline & Very good, good, average, below average & \\
\hline & Colombia: & $1=$ Extremely well, Very \\
\hline & Have you got on well at school? & well, Moderately well \\
\hline & Not at all, slightly, moderately well, very, extremely & $2=$ Slightly, Not at all well \\
\hline
\end{tabular}

\subsection{Assessment of Physical Inactivity (PI)}

The measure of physical inactivity was based on a measure of moderate to vigorous PA (MVPA) based on an item "In the past 7 days: on how many days were you physically active for a total of at least 60 min?" and on a measure of Vigorous PA (VPA) based on an item: "Outside school hours: How many hours a week do you usually exercise so much that you get out of breath or sweat?" in both samples. Additionally, other dimensions of 
PA e.g., frequency, duration, type of activities, outdoor PA, and type and time of transport were also compared in both samples. Table 1 presents the compared items from the Danish, and the Colombian questionnaires, as well as the operationalization of these variables.

In Denmark assessment of MVPA was made through the question "How much time ( $<1$ hour, or $\geq 1$ hour) do you spend each day on moving, for example, cycling, walking, playing, playing sports, and so on?" This variable was categorized into $\geq 1$ hour per day ( $=\geq 420$ minutes per week) indicating being physically active, or $<1$ hour per day indicating being physically inactive. This cut-off correspond to the new Nordic guidelines on PA and to the WHO global recommendations on PA for health of 60 minutes of moderate to vigorous PA (MVPA) per day, for children and adolescents (http://www.norden.org/en/news-and-events/news/new-nordic-nutritionrecommendations-focus-on-quality-and-the-whole-diet/; WHO, 2010). For Colombians, the ISCOLE questionnaire (Katzmarzyk, Barreira, Broyles, Champagne, Chaput, Fogelholm, Hu, Johnson, Kuriyan, Kurpad, Lambert, Maher, Maia, Matsudo, Olds, Onywera, Sarmiento, Standage, Tremblay, Tudor-Locke, Zhao \& Church, 2013) assesses PA as "How many days were you physically active for a total of at least 60 minutes per day? ("All the time you spent on activities that increased your heart rate and made you breathe hard ( $\mathbf{(})$ ". The answers provided are number of days with at least 60 minutes. PA was categorized as $\geq 5$ days per week with at least 60 minutes per day ( $=\geq 300$ minutes per week) indicating being physically active, or $<5$ days per week with at least 60 minutes per day indicating being physically inactive. Due to the difference in the item formulations measuring PA, we used a cut-off that allowed us to make comparisons between the groups.

\subsection{Statistical Analyses}

Prevalence was reported as a percentage with $95 \%$ confidence intervals (lower and upper limits). Significant differences between the Colombian and the Danish samples were stated, when the confidence intervals of the proportions did not overlap. For comparisons between the Danish students and the students with non-Danish background, Chi-Square tests were used. Bivariate logistic regression analyses where conducted to test associations between physical inactivity and the potentially related variables. Those variables statistically significant in theses bivariate models were included in the two multifactorial logistic regression models that analysed possible confounding separately for the Danish sample (model 1) and for the Colombian sample (model 2). Separate analyses were conducted because the item formulations were not exactly identical in the Danish and the Colombian questionnaires. All models were adjusted by sex. The operationalization of the variables is presented in Table 1. Goodness-of-Fit of each model was tested with the deviance coefficient and the Hosmer-Lemeshow statistics. The level of significance was set at $5 \%$, and the confidence intervals (CI) were established at the $95 \%$ level. All statistical analyses were carried out using IBM SPSS Statistics for Windows v21.0 (IBM Corp., Armonk, NY).

\subsection{Ethical Considerations}

In Denmark, at the time of this survey, there was no formal agency for ethical approval of school surveys. Therefore, researchers asked the school leader, the board of students and the board of parents in each of the participating schools for an approval of the study (Vinther-Larsen et al., 2010). All students who answered the questionnaire voluntarily had informed written consent from their parents. In Colombia, the Ethical and Research Committee from the Nursing Faculty, at the University of Antioquia, Colombia (ACTA ENFER, ENFER04), approved the study. Participation was a voluntary after informed and written consent from both, parents and students.

\section{Results}

Table 2 presents differences regarding socioeconomic and demographic characteristics between the groups. Almost all the Colombian students $(90.0 \%)$ came from the two lowest socioeconomic levels while far less Danish students belonged to the lowest socioeconomic levels, especially those with only Danish background $(17.9 \%)$. The percentage of girls was slightly higher in the Danish sample than it was in the Colombian. Living only with the mother was almost the same among the groups. The students with non-Danish background living in Denmark had lower family affluence (Strata 0 and 1) than students with Danish background. 
Table 2. Characterization of the students (13-14 years old) from families with lower socioeconomic background from Denmark and Colombia

\begin{tabular}{llll}
\hline $\mathbf{N}=\mathbf{1 , 3 7 4}$ & \multicolumn{3}{l}{ Background } \\
\hline Variable & $\begin{array}{l}\text { Only Danish background } \\
(\mathrm{n}=1,222, \%)\end{array}$ & $\begin{array}{l}\text { Non-Danish background } \\
(\mathrm{n}=152, \%)\end{array}$ & $\begin{array}{l}\text { Colombian } \\
(\mathrm{n}=426, \%)\end{array}$ \\
\hline Sex & $547(44.8)$ & $73(48.0)$ & $222(52.0)$ \\
Boys & $675(55.5)$ & $79(52.0)$ & $204(48.0)$ \\
Girls & & & \\
Family affluence ${ }^{a}$ & $1003(82.1)$ & $104(68.4)^{*}$ & $41(10.0)$ \\
Strata 2 & $199(16.3)$ & $41(27.0)$ & $205(52.0)$ \\
Strata 1 & $20(1.6)$ & $7(4.6)$ & $151(38.0)$ \\
Strata 0 & $359(29.4)$ & $45(29.6)$ & $134(31.5)$ \\
Living only with mother (YES) & & $63(41.4) *$ & $43(10.1)^{\mathrm{b}}$ \\
Religion & $801(65.5)$ & $89(58.6)$ & $378(89.0)$ \\
Protestant (Den Danske Folkekirke) & $421(34.5)$ & & \\
Others/not religious, catholic & & & \\
\hline
\end{tabular}

"Significant difference between the Danish and non-Danish students based on chi-square test over all categories with $\mathrm{p}<0.05$; ${ }^{\mathrm{a}}$ Strata represents the socioeconomic classification according to the family affluence, i.e., FAS-index in Denmark ( 0 the lowest to 5 the highest), and in Colombia according to the Family Socioeconomic Classification Index SISBEN (1 the poorest to 6 the richest). ${ }^{b}$ Other religion than Catholic

\subsection{Prevalence of PA and Sedentary Behaviours}

As shown in Table 3 the prevalence of physical inactivity was much higher among Colombian students (74.6\%) compared to Danish students (25.2\%) and students with a non-Danish background living in Denmark (21.1\%). Colombian students reported longer screen time than both groups of students from Denmark. Almost three times as many students from Colombia engaged in only up to one hour sports/exercise after school when compared to both Danish groups (Table 3). Belonging to a club was more common among students with Danish background (40.8\%) compared to Colombian students $(28.6 \%)$. Accordingly, the percentage of students who spent less than one hour/week on sports after school was higher among Colombian students than among both Danish groups. More Danish students reported more than 2 hours/week time for physical education at school than Colombian students did.

Most of the Colombian students (81.4\%) had inactive daily transportation to school, mainly by bus or tram, whereas this was less than $20 \%$ among Danish. For both, students with Danish and non-Danish background, the active transportation to school, i.e. walking, was common (65.0\%) compared to $8.4 \%$ for Colombians. Out of the Danish students who had active transportation around $80 \%$ spent between 1 and 30 minutes on journey per day, whereas in $20.9 \%$ of Colombians, it took more than 60 minutes. Comparing Danish students with students with non-Danish background PI was lower, time spent on computer was higher, time spent on sports after school lower, physical education at school higher and belonging to a club also was lower for the latter group. Although the absolute percentages did not differ very much these differences were still significant at $\mathrm{p}<0.05$. 
Table 3. Comparisons of the prevalences and confidence intervals (95\% CIs) of physical inactivity and sedentary behaviors in the three subgroups of students (13-14 years old) from socioeconomically disadvantaged families from Denmark and Colombia

\begin{tabular}{|c|c|c|c|c|}
\hline \multicolumn{3}{|l|}{$\mathrm{N}=1374$} & \multicolumn{2}{|l|}{ Background } \\
\hline $\begin{array}{l}\text { Physical Activity } \quad \text { and } \\
\text { Sedentary } \\
\text { Behaviors }\end{array}$ & & Danish & $\begin{array}{l}\text { Non-Danish living in } \\
\text { Denmark }\end{array}$ & Colombian \\
\hline \multirow{3}{*}{ Physically active ( $\geq 60 \mathrm{~min} /$ day $)$} & & $\begin{array}{l}\mathrm{n}=1222(\%, 95 \% \\
\mathrm{CI})\end{array}$ & $\mathrm{n}=152(\%, 95 \% \mathrm{CI})$ & $\begin{array}{l}\mathrm{n}=426(\%, 95 \% \\
\mathrm{CI})\end{array}$ \\
\hline & no & $\begin{array}{l}308(\mathbf{2 5 . 2} \\
22.8-27.6)\end{array}$ & $32(21.1,14.5-27.5)^{*}$ & $\begin{array}{l}318(\mathbf{7 4 . 6} \\
70.5-78.7)^{\wedge}\end{array}$ \\
\hline & yes & $\begin{array}{l}900(73.7, \\
71.2-76.1)\end{array}$ & $115(\mathbf{7 5 . 7}, 68.8-82.5)$ & $\begin{array}{l}108(\mathbf{2 5 . 4} \\
21.3-29.5)\end{array}$ \\
\hline \multirow[t]{4}{*}{ Time spent on TV (per day) } & none & $4(\mathbf{2 . 8}, 1.87-3.72)$ & $8(\mathbf{5 . 3}, 1.71-8.81)$ & $35(\mathbf{8 . 0}, 5.4-12.3)$ \\
\hline & $<=1$ hour & $\begin{array}{l}485(39.7 \\
36.9-42.4)\end{array}$ & $65(42.8,34.9-50.6)$ & $40(\mathbf{9 . 5}, 6.7-12.3)$ \\
\hline & $>1-4$ hour & $\begin{array}{l}59(\mathbf{4 9 . 0} \\
46.2-51.8)\end{array}$ & $64(42.1,34.2-50.0)$ & $\begin{array}{l}311(\mathbf{7 3 . 0} \\
68.8-77.2)\end{array}$ \\
\hline & $>4$ hour & $90(7.4,5.9-8.8)$ & $10(\mathbf{6 . 6}, 2.65-10.55)$ & $40(9.5,6.7-12.3)$ \\
\hline \multirow[t]{4}{*}{ Computer time $\left(\right.$ per day) ${ }^{\mathrm{a}^{*}}$} & none & $\begin{array}{l}314(\mathbf{2 5 . 7} \\
23.2-28.1)\end{array}$ & $31(\mathbf{2 0 . 4}, 14.0-26.8)^{*}$ & $\begin{array}{l}59(\mathbf{1 4 . 0} \\
10.7-17.3)\end{array}$ \\
\hline & $<=1$ hour & $\begin{array}{l}513(\mathbf{4 2 . 0} \\
39.2-44.8)\end{array}$ & $64(42.1,34.2-50.0)$ & $49(\mathbf{1 1 . 5}, 8.5-14.5)$ \\
\hline & $>1$-4hour & $\begin{array}{l}297(\mathbf{2 4 . 3} \\
21.9-26.7)\end{array}$ & $36(23.7,17.0-30.5)$ & $\begin{array}{l}256(\mathbf{6 0 . 0} \\
55.4-64.6)\end{array}$ \\
\hline & $>4$ hour & $82(6.7,5.3-8.1)$ & $16(\mathbf{1 0 . 5}, 5.6-15.4)$ & $\begin{array}{l}62(\mathbf{1 4 . 5} \\
11.6-17.8)\end{array}$ \\
\hline Belonging to a club/team & yes & $\begin{array}{l}492(\mathbf{4 0 . 8} \\
38.0-43.5)\end{array}$ & $52(\mathbf{3 5 . 4}, 27.8-43.0)^{*}$ & $\begin{array}{l}122(\mathbf{2 8 . 6} \\
24.3-32.9)\end{array}$ \\
\hline $\begin{array}{l}\text { Time spent on sport/exercise } \\
\text { after school: }{ }^{\mathrm{b}}\end{array}$ & $<=1 \mathrm{~h} /$ week & $\begin{array}{l}451(37.3 \\
34.6-40.0)\end{array}$ & $51(\mathbf{3 4 . 5}, 26.5-41.5)^{*}$ & $\begin{array}{l}260(\mathbf{6 1 . 5} \\
56.9-66.1)\end{array}$ \\
\hline PE at school: ${ }^{* a}$ & $>2$ hours per week & $\begin{array}{l}104(\mathbf{8 . 5} \\
6.9-10.2)\end{array}$ & $20(\mathbf{1 3 . 1}, 7.8-15.5)^{*}$ & $21(\mathbf{5 . 0}, 2.9-7.1)$ \\
\hline \multirow[t]{6}{*}{$\begin{array}{l}\text { Time spent on journey to school } \\
\text { per day }{ }^{c}\end{array}$} & & $988^{+}$ & $125^{+}$ & $426^{++}$ \\
\hline & $<5 \min$ & $\begin{array}{l}247(\mathbf{2 5 . 0} \\
22.3-27.7)\end{array}$ & $39(\mathbf{3 1 . 2}, 23.1-39.3)^{*}$ & $5(\mathbf{1 . 2}, 0.2-2.2)$ \\
\hline & $6-15 \mathrm{~min}$ & $\begin{array}{l}470(47.6 \\
44.5-50.7)\end{array}$ & $47(\mathbf{3 7 . 6}, 29.1-46.1)$ & $39(9.2,6.5-11.9)$ \\
\hline & $16-30 \mathrm{~min}$ & $84(8.5,6.7-10.2)$ & $11(\mathbf{8 . 8}, 3.8-13.8)$ & $\begin{array}{l}114(\mathbf{2 6 . 8} \\
22.6-31.0)\end{array}$ \\
\hline & $31-60 \mathrm{~min}$ & $\begin{array}{l}13(\mathbf{1 . 3 1} \\
0.6-2.02)\end{array}$ & $1(\mathbf{0 . 8}, 0.7-2.3)$ & $\begin{array}{l}179(\mathbf{4 2 . 0} \\
37.3-46.7)\end{array}$ \\
\hline & $>60 \mathrm{~min}$ & $0(\mathbf{0 . 0 0})$ & $0(\mathbf{0 . 0 0 )}$ & $\begin{array}{l}89(\mathbf{2 0 . 9} \\
17.0-24.8)\end{array}$ \\
\hline \multirow[t]{3}{*}{ Main transportation } & Walking, bicycle, etc. & $\begin{array}{l}786(\mathbf{6 5 . 0} \\
62.5-67.5)\end{array}$ & $96(\mathbf{6 5 . 3}, 57.6-73.0)$ & $35(8.4,6.6-10.2)$ \\
\hline & $\begin{array}{l}\text { Bus, tram, car, } \\
\text { underground }\end{array}$ & $\begin{array}{l}223(\mathbf{1 8 . 4} \\
16.3-20.5)\end{array}$ & $23(\mathbf{1 5 . 6}, 9.7-21.5)$ & $\begin{array}{l}341(\mathbf{8 1 . 4} \\
78.8-84.0)\end{array}$ \\
\hline & $\begin{array}{l}\text { Sometimes walking, } \\
\text { car, bus }\end{array}$ & $\begin{array}{l}200(\mathbf{1 6 . 5} \\
14.5-18.5)\end{array}$ & $28(\mathbf{1 9 . 0}, 12.7-25.3)$ & $\begin{array}{l}43(\mathbf{1 0 . 3} \\
8.30-12.3)\end{array}$ \\
\hline
\end{tabular}

\footnotetext{
"Significant difference between the Danish and non-Danish students based on chi-square tests with $\mathrm{p}<0.05^{\wedge}$ Colombian dataset physically active defined as "days per week being physically active for a total of at least $60 \mathrm{~min}$, with increased heart and breath rate"; no=0-4 days, yes $=\geq 5$ days; "Total time of active transportation (from home to school and back) only for those who had active transportation to school; ${ }^{++}$Time of inactive transportation only for one way: from home to school; Total can vary due to missing values in each category.
} 


\subsection{Factors Associated with Physical Inactivity (PI)}

Table 4 shows associations between physical inactivity (PI), some sedentary behaviours and psychosocial dimensions, separately for Danish and Colombian participants. In both groups, low time spent on sports after school and lower self-perceived health were associated with PI. Sedentary behaviours (time in front of screen) were also positively associated with PI. However, only time spent on computer ( $\geq 4$ hours per day) was significantly associated with being physically inactive for all students. Time spent on watching TV was not associated with PI in any group.

The students from Colombia who did not belong to any sports club/teams were more likely to be physically inactive than those who belonged to one. Time spent on inactive transportation was positively associated with PI for Colombians, as well as the age of the mother was negatively associated with PI. Additionally, intrinsic motivation to PA was a protective factor for PI in this group.

In addition, Danish students who rated their performance at school not so good, and those who perceived the enjoyment at school not so good, were more likely to be physically inactive than those who rated these school aspects as very good or good. Danish students whose father was drinking alcohol weekly were more likely to be physically inactive compared to their counterparts whose father did not. Moreover, in the Danish group, students living only with the mother had lower odds of being physically inactive than those living with either parents or whatever other combination.

Table 4. Variables associated with being physically inactive for all Danish students compared to Colombians

\begin{tabular}{|c|c|c|c|c|c|c|c|}
\hline \multirow{2}{*}{$\begin{array}{l}\text { Physically inactive } \\
\text { no/yes }\end{array}$} & & \multicolumn{4}{|c|}{ All Danish students ${ }^{1}$} & \multicolumn{2}{|c|}{ Colombian students $^{2}$} \\
\hline & & OR & $95 \% \mathrm{CI}$ & p-value & OR & $95 \% \mathrm{CI}$ & p-value \\
\hline \multirow[t]{2}{*}{$\begin{array}{l}\text { Beloning to club/sports } \\
\text { teams }\end{array}$} & yes & & & & Ref & & \\
\hline & no & & & & 2.29 & $1.04-5.04$ & 0.039 \\
\hline \multirow[t]{3}{*}{ Time spent on computer } & None & Ref & & 0.025 & Ref & & 0.006 \\
\hline & $30 \mathrm{~min}$ to 4 hours & 1.26 & $0.74-2.15$ & 0.398 & 1.99 & $1.05-3.93$ & 0.046 \\
\hline & $>4$ hours & 0.82 & $0.50-1.36$ & 0.458 & 0.85 & $0.35-2.06$ & 0.715 \\
\hline \multirow[t]{2}{*}{$\begin{array}{l}\text { Time spent on sports after } \\
\text { school }\end{array}$} & $<4$ hrs per week & Ref & & & Ref & & \\
\hline & $>4 \mathrm{hrs}$ per week & 0.20 & $0.14-0.28$ & $<0.001$ & 0.87 & $0.76-0.99$ & 0.044 \\
\hline $\begin{array}{l}\text { Time on inactive journey to } \\
\text { school }\end{array}$ & (> 30min/day) & & & & $1.77^{\&}$ & $1.03-3.02$ & $\mathbf{0 . 0 3 7}$ \\
\hline \multirow[t]{2}{*}{ Self-perceived health } & very good/good & Ref & & & Ref & & \\
\hline & not so good & 1.46 & $1.06-2.04$ & 0.026 & 1.72 & $1.03-2.89$ & 0.040 \\
\hline \multirow[t]{2}{*}{$\begin{array}{l}\text { Perceived performance at } \\
\text { school }\end{array}$} & very good/good & Ref & & & & & \\
\hline & not so good & 2.01 & $1.53-2.66$ & $<0.001$ & & & \\
\hline \multirow[t]{2}{*}{$\begin{array}{l}\text { Perceived } \\
\text { school }\end{array}$} & very good/good & Ref & & & & & \\
\hline & not so good & 1.50 & $1.14-1.98$ & 0.004 & & & \\
\hline \multirow[t]{2}{*}{ Intrinsic Motivation to PI } & not giving importance & & & & Ref & & \\
\hline & $\begin{array}{ll}\text { giving } & \text { some/high } \\
\text { importance } & \end{array}$ & & & & 0.20 & $0.09-0.45$ & 0.023 \\
\hline \multirow[t]{2}{*}{ Father drinking weekly } & no & Ref & & & & & \\
\hline & yes & 1.30 & $1.01-1.67$ & 0.040 & & & \\
\hline \multirow[t]{2}{*}{ Living with parents } & with both parents & Ref & & & & & \\
\hline & only with the mother & 0.67 & $0.49-0.91$ & 0.010 & & & \\
\hline Age of the mother & (years) & & & & 0.95 & $0.92-0.99$ & 0.020 \\
\hline
\end{tabular}

Note. All models adjusted by sex, socioeconomic strata, familiar background, and all other variables in the table.

${ }^{\star}$ time for journey to school (>30min versus less) ${ }^{1}$ Model for Danes $R^{2}=21,{ }^{2}$ Model for Colombians $R^{2}=24.5$. 


\section{Discussion}

Our findings add new specific information on levels of PA and sedentary behaviours among Scandinavian compared to Colombian adolescents, from families with lower levels of affluence to the existing knowledge on geographical, social, and ethnic disparities of PA. The results clearly indicate that Danish adolescents have higher levels of PA and a lower prevalence of sedentary behaviours compared to Colombian adolescents. Danish adolescents participate more often in organized sports and consequently spend more time on sports after school, they are more likely actively commute to school, and spend less time on screen viewing than Colombians do. It is also important to note that only slightly different patterns of sedentary behaviours were found among adolescent with non-Danish background and overall their PA is very similar to that of students born in Denmark.

Ethnicity covers race, nationality, citizenship, migration status and is a very complicated issue of inequality in the social context. Ethnic disparities in levels of PA between Black and White adolescents and between Afro-American and American adolescents have been previously reported (Whitt-Glover, Taylor, Floyd, Yore, Yancey, \& Matthews, 2008; Lawman \& Wilson, 2012; Mc Veigh \& Meiring, 2014). In line with our results, these studies found that Black African and Afro-American adolescents, as well as Latin-American adolescents remain the less physically active and the more sedentary when compared to White adolescents. The same studies also showed an association between ethnic disparities and physical inactivity and overweight/obesity. In our study, the prevalence of physical inactivity was much higher among Colombian compared with Danish adolescents. In agreement with our findings, low levels of PA have been found among other Latin-American populations, Colombian and African adolescents (Jimenez-Pabón, Kelly, \& Reilly, 2010; Peltzer, 2010; Caballero, Rojas Sánchez, \& Gamboa Delgado, 2014). In a recent study in Kenya using the ISCOLE-questionnaire, over half of the children reported spending two days or less being physically active for more than 60 minutes, which agrees to our findings (Muthuri, Wachira, Onywera, \& Tremblay, 2014). Research shows that parents with low income may discourage adolescents' PA participation because of the cost, lack of opportunities for participation, and transport barriers (Smith, Grunseit, Hardy, King, Wolfenden, \& Milat, 2010).

Smith et al. (2010) found that the number of barriers was inversely related to adolescents' time spent in organised activity, i.e. sports clubs/teams, which is in accordance with our results. Our study highlights the important relationship between adolescents' PA and belonging to a sport club/team, showing that being in a sports club is a protective factor for PI. Danish adolescents and especially those with Danish background participate in a club and exercise more frequently after school compared to Colombians. Moreover, the physical environment i.e. objective and perceived characteristics of the physical context in which adolescents spend their time, namely local conditions (e.g., home, neighbourhood, crime area), recreational infrastructure (e.g., access to recreational facilities, play areas), and transport infrastructure (e.g. traffic density) are associated with adolescents' participation in PA (Lawman \& Wilson, 2012; Eyre, 2015; Babey et al., 2015). The different physical environments of the countries Denmark and Colombia might therefore explain the observed differences in PA level outlined above. In Scandinavia, the presence of public lawns, meadows, and hilly forests is high and even during the wintertime, foot, and bike paths and other public spaces are generally illuminated. Further, sports clubs, and local recreational facilities in neighbourhoods are available and maintained by the government. Hence, belonging to a club or participating in some sport team is affordable and accessible for the youth. That is not the case in Colombia, even though in deprived areas some organized sports have been implemented. However, they are not always accessible for adolescents from these neighbourhoods, especially for girls whom need company from an adult because of the insecurity of their neighbourhoods, which is supported by previous research (Graham et al., 2014). A significant negative association between adolescents' PA and crime area or area deprivation has also been documented by others (Gómez, Johnson, Selva, \& Sallis JF, 2004; Brodersen, Steptoe, Williamson, \& Wardle, 2005; Lawman \& Wilson, 2015). Therefore, belonging to a sport club/team is depending primarily on the economic wealth of the family as well as on the availability of recreation areas and facilities in neighbourhoods where the adolescents live (Davison \& Lawson, 2006).

Another factor contributing to higher PA among Danish adolescents was their higher degree of actively commuting to school (89\%). In Denmark, the schools are often located in the neighbourhoods where adolescents live. Public transportation and traffic density is low and the use of the bicycle as main transportation to school is very common. In contrast, the physical environment conditions and traffic conditions differ considerably in the city of Medellin, which has a high traffic density and dangerous environmental attributes. Most of the adolescents in our study attending the largest public school in Medellin live far away from their school, and their daily time spent on transportation is around one hour in metro or bus. Additionally, it is unsafe to take the bicycle to commute to school due to the poor infrastructure where for instance, sidewalks and bike lanes are scarce. Adolescents who live close to schools are more likely to commute actively to school. In this respect, the parent's 
perceptions of the safety of the area promote this practice (Lawmen \& Wilson, 2012; Davison \& Lawson, 2006).

Colombian adolescents spend much more time in front of a screen compared to Danish adolescents. In agreement with our findings, prior research in adolescents from Brazil, Mexico and Kenya has found high levels of sedentary behaviours (Azevedo et al., 2014; Lajous, Chavarro, Peterson, Hernández-Prado, Cruz-Valdéz, Hernández-Avila, \& Lazcano-Ponce, 2009; Muthuri et al., 2014). In Kenya, using also the ISCOLE-questionnaire, the high level of PI found in this group was similar to the observed PI level in the Colombian adolescents. Regardless of ethnic background, adolescents from South Africa who spend more than four hours per day in front of the screen were almost twice as likely to be overweight (Mc Veigh \& Meiring, 2014). In fact, daily screen viewing in excess of two hours is associated with reduced physical and psychosocial health in adolescents (Saunders et al., 2014; Abally et al., 2013).

In this study, adolescents from both Denmark and Colombia with low levels of PA felt less well and reported poorer perceived health. This is in line with prior findings where reduced health related quality of life having been found to be associated with low levels of PA in adolescents (European Commission, 2013; Lawman \& Wilson, 2012).

Moreover, the family environment has a significant influence on both, PA and dietary intake (Gruber \& Haldeman, 2009). Level of support offered by parents, and whether they are role models by their own levels of PA can influence the time adolescents spend in PA or on screen viewing (Gustafson \& Rhodes, 2006). In our study, associations between several family related variables and PI were found. For the Danish group, PI was less common among adolescents living only with the mother than among students living with both parents. Additionally, PI was related to the presence of a father who often drinks alcohol. Among Colombian adolescents, the age of the mother was positively associated with PI; i.e. the younger the mother the more active the child. Parents may determine adolescents' exposure to a number of factors that are enablers or barriers to PA, such as motivation to engage in PA and that may explain our findings in line with previous research (Gustafson \& Rhodes, 2006; Lawman \& Wilson, 2012). Several mechanisms are underpinning parental impact on PI such as direct modelling of PA, establishing or eliminating barriers to PA or sports, and positively reinforcing adolescents for participation in sports (Henriksen et al., 2015). According to our findings, we also posit the socioeconomic-environmental factors as determinants of PI in youth people from families with lower affluence, rather than support the statement that PA is a determinant of health and illness per se, as previously have been posited (Colley et al., 2011).

There are several limitations to this study. Actually, dietary habits could be confounding several of the found associations with PI, but this information was not available to us. Regarding assessment of PA for the Danish sample, the unit for measuring PA was hours per day, while for the Colombian it was number of days per week with at least one hour PA per day. Due to this, we had to apply different cut-offs for the two samples; hence the cut-off for the Danish sample was equivalent to a higher number of PA minutes per week. However, the different cut-offs used are not likely to explain the differences on level of PA observed, because if a stricter cut-off would have been applied for the Colombian sample (like the one for the Danish sample) the observed difference between Colombian and Danish adolescent would have been even larger. In addition, we argue for the large similarities between the questionnaires regarding: (i) the construct e.g. habitual PA (ii) the dimension of PA e.g., frequency, duration, and (iii) the type of activities e.g. sport, recreational, and transport. Both questionnaires measure the same construct, i.e. time spent being moderate-to vigorously active outside school (minutes), which allowed us compare MVPA and VPA and the dimensions of PA between the groups, in line with prior research (World Health Organization, 2010; Muthuri et al., 2014; Chinapaw, Mokkink, van Poppel, van Mechelen \& Terwee, 2010; Katzmarzyk et al., 2013; Henriksen et al., 2015). Additionally, the other measures of sedentary behaviours and additional measures of PA consistently confirmed that Colombians were less commonly active compared to Danish, independently of the cut-off used to define being physically active. Moreover, when measuring PA, recall bias must be taken into account. However, in our samples this bias would be in the same direction in both groups. Further, PA questionnaires are easy to administer and acceptable to study participants whereas objective methods provide do not information about the type of PA behaviour or in what context and where the activity was performed e.g. active transport kind of sports (Chinapow et al., 2010; Lawman \& Wilson, 2015). Furthermore, the cross sectional design in this study limits inferences of a longitudinal or causal nature. Due to different selection effects (response rate, geographical coverage) the results impeding to extrapolate neither to the Danish nor to Colombians general adolescent population. Moreover, the different timing of the data collections in Denmark and Colombia could be of concern. However, because in Denmark, levels of obesity and to some extend of physical activity have reached a plateau (www.si-folkesundhed.dk and www.hbsc.dk) whereas in developing countries it is still increasing, we assume that the earlier data collection in Denmark 
cannot fully explain the higher PA levels found in Colombia. The samples were selected for belonging to a low SES family with different measures of SES according to the Danish or to the Colombian index. We are aware that even though both samples represent lower socio-economic strata of the given country, absolute differences on levels of PI would remain between Danish and Colombian students from the lowest socioeconomic background. Within the sample from Denmark, we separated into those born in Denmark and those with non-Danish background while being aware that this is a relatively crude measure for ethnic background. Further, the sample size of adolescents with non-Danish background is relatively small in this sample, which limits detecting differences between students with Danish-background and students with non-Danish background. Previously, it has been reported that students with lower SES in Denmark are underrepresented in the Danish Youth Cohort (Vinther-Larsen et al., 2010).

We conclude from our study that most Colombian adolescents with lower SES are not meeting the recommendation of accumulating at least 60 minutes per day of moderate-to-vigorous intensity PA for positive health outcomes as most Danish adolescents with lower SES do, independently of their ethnic background. We assume that the physical and social environment in the neighbourhoods where adolescents live differ for Danish and Columbian adolescents and that this contributes to the differences in levels of PA and sedentary behaviours observed between the two study populations.In addition, socio-familial aspects discouraging adolescents to be physically active and diminishing the control of extended screen time might also contribute to the high level of PI especially among Colombian students. These findings further confirm the need to promote outdoor environments for sports/exercise among adolescents from families with low socioeconomic conditions. Otherwise, obesity and obesity related conditions should continue affecting the young population in both regions. Additionally, interventions aimed at increasing health-enhancing PA among adolescents should specifically consider the described barriers. One possible solution might be to support infrastructure that facilitates active living as the default option of adolescent's life with an additional incorporation of their relatives' engagement. According to our results, physical inactivity must be considered as result from the individual's interaction with his or her social environment rather than as result of an individual lifestyle alone.

\section{Acknowledgments}

We thank all the students from Colombia and Denmark who participated in the study. We thank Dr. Mathilde Vinther Larsen for providing data and background information on the Danish Youth Cohort (Ungeshverdag.dk).

The author(s) disclosed receipt of the following financial support for the research, authorship, and or publication of this article: Comité para el Desarrollo de la Investigación (CODI), Vicerrectoría de Investigación (project ENFER04-2004), University of Antioquia, Colombia.

POC contributed with the Colombian acquisition of data from the study "Meanings and Practices of Physical Activity in Obese and Overweight Students from Low Socioeconomic Levels at a Public School in Medellín, Colombia", with the conception and study design, data analysis and interpretation of data, as well as written the manuscript.

CS contributed with the acquisition of data from the Danish Youth Cohort (Ungeshverdag.dk), with the study design, interpretation of data, involved in drafting and revising critically the manuscript.

\section{Competing Interests Statement}

The authors declare that there is no conflict of interests regarding the publication of this paper.

\section{References}

Aballay, L. R., Eynard, A. R., Díaz, M. P., Navarro, A., \& Muñoz, S. E. (2013). Overweight and obesity: A review of their relationship to metabolic syndrome, cardiovascular disease, and cancer in South America. Nutr Rev, 71(3), 168-179. http://dx.doi.org/10.1111/j.1753-4887.2012.00533.x

Azevedo, M. R., Menezes, A. M., Assunção, M. C., Gonçalves, H., Arumi, I., Horta, B. L., \& Hallal, P. C. (2014). Tracking of physical activity during adolescence: The 1993 Pelotas Birth Cohort, Brazil. Revista de Saúde Pública, 48(6), 925-930. http://dx.doi.org/10.1590/S0034-8910.2014048005313

Babey, S. H., Wolstein, J., \& Diamant, A. L. (2015). Role models and social supports related to adolescent physical activity and overweight/obesity. Policy Brief UCLA Cent Health Policy Res, 3, 1-8.

Brodersen, N. H., Steptoe, A., Williamson, S., \& Wardle, J. (2005). Sociodemographic, developmental, environmental, and psychological correlates of physical activity and sedentary behavior at age 11 to 12 . Ann Behav Med, 29(1), 2-11. http://dx.doi.org/10.1207/s15324796abm2901_2

Caballero, L. G., Rojas Sánchez, L. Z., \& Gamboa Delgado, E. M. (2014). Overweight and obesity in Colombian 
college students and its association with physical activity. Nutr Hosp, 31(2), 629-36.

Chinapaw, M. J., Mokkink, L. B., van Poppel, M. N., van Mechelen, W., \& Terwee, C. B. (2010). Physical activity questionnaires for youth: A systematic review of measurement properties. Sports Med, 40(7), 539-63. http://dx.doi.org/10.2165/11530770-000000000-00000

Colley, R., Garriguet, D., Janssen, I., Craig, C. L., Clarke, J., \& Tremblay, M. S. (2011). Physical activity of Canadian children and youth: Accelerometer results from the 2007 to 2009 Canadian Health Measures Survey. Statistics Canada, Catalogue no. 82-003-XPE. Health Reports, 22(1).

Currie, C., Molcho, M., Boyce, W., Holstein, B., Torsheim, T., \& Richter, M. (2008). Researching health inequalities in adolescents: The development of the HBSC Family Affluence Scale. Soc Sci Med, 66, 1429-36. http://dx.doi.org/10.1016/j.socscimed.2007.11.024

Currie, C., Zanotti, C., Morgan, A., Currie, D., de Looze, M., Roberts, C., ... Barnekow, V. (2012). Social determinants of health and well-being among young people. Health Behaviour in School-aged Children (HBSC) study: International report from the 2009/2010 survey. Health Policy for Children and Adolescents, (6). PART 2. WHO Regional Office for Europe, Copenhagen.

Davison, K. K., \& Lawson, C. T. (2006). Do attributes in the physical environment influence children's physical activity? A review of the literature. Int J Behav Nutr Phys Act, 27(3), 19. http://dx.doi.org/10.1186/ 1479-5868-3-19

Departamento Nacional de Planeación. Sistema de identificación de potenciales beneficiarios de programas sociales (SISBEN) 2007. (2015, December 28). Colombia. Retrieved from https://www.sisben.gov.co

Espinel, P., Laws, R., Bonfiglioli, C., Hardy, L. L., \& King, L. (2013). Investigating the media power of a population health monitoring survey: Case study of the NSW Schools Physical Activity and Nutrition Survey (SPANS). Aust N Z J Public Health, 37(3), 284-289. http://dx.doi.org/10.1111/1753-6405.12072

European Commission. (2013). Physical education and sport at school in Europe - Eurydice Report. Luxembourg: Publications Office of the European Union. ISBN 978-92-9201-407-0.

Eyre, E. L. J., Duncan, M. J., Birch, S. L., Cox, V., \& Blackett, M. (2015). Physical activity patterns of ethnic children from low socio-economic environments within the UK. J Sports Sci, 33(3), 232-242. http://dx.doi.org/10.1080/02640414.2014.934706

Gómez, J. E., Johnson, B. A., Selva, M., \& Sallis, J. F. (2004). Violent crime and outdoor physical activity among inner-city youth. Prev Med, 39(5), 876-81. http://dx.doi.org/10.1016/j.ypmed.2004.03.019

Graham, D. J., Bauer, K., Friend, S., Barr-Anderson, D. J., \& Nuemark-Sztainer, D. (2014). Personal, behavioural, and socioenviromental correlates of physical activity among adolescent girls. Cross-sectional and longitudinal associations. J Phys Activity Health, 11, 51-61. http://dx.doi.org/10.1123/jpah.2011-0239

Gruber, K. J., \& Haldeman, L. A. (2009). Using the family to combat childhood and adult obesity. Prev Chronic Dis., 6(3), A106.

Hamrani, A., Mehdad, S., El Kari, K., El Hamdouchi, A., El Menchawy, I., Belghiti, H., ... Aguenaou, H. (2015). A review of family and environmental correlates of health behaviors in high-risk youth. Public Health Nutr, 18(10), 1793-1800. http://dx.doi.org/10.1017/S1368980014002274

Hardy, L. L., King, L., Espinel, P., Cosgrove, C., \& Bauman, A. (2010). NSW Schools Physical Activity and Nutrition Survey (SPANS): Full report. NSW Ministry of Health, Sydney.

Henriksen, P. W., Rayce, S. B., Melkevik, O., Due, P., \& Holstein, B. E. (2015). Social background, bullying, and physical inactivity: National study of 11- to 15-year-olds. Scand J Med Sci Sports. http://dx.doi.org/10. $1111 /$ sms. 12574

Instituto Colombiano de Bienestar Familiar. Encuesta Nacional de la Situación nutricional en Colombia (ENSIN), 2010. (2011). Retrieved from http://www.icbf.gov.co/bienestar/ENSIN

Jiménez-Pavón, D., Kelly, J., \& Reilly, J. J. (2010). Associations between objectively measured habitual physical activity and adiposity in children and adolescents: Systematic review. Int $J$ Pediatr Obesity, 5, 3-18. http://dx.doi.org/10.3109/17477160903067601

Katzmarzyk, P. T., Barreira, T. V., Broyles, S. T., Champagne, C. M., Chaput, J. P., Fogelholm, M., ... Church, T. S. (2013). The International Study of Childhood Obesity, Lifestyle and the Environment (ISCOLE): Design and methods. BMC Public Health, 13(1), 900. http://dx.doi.org/10.1186/1471-2458-13-900 
Lajous, M., Chavarro, J., Peterson, K. E., Hernández-Prado, B., Cruz-Valdéz, A., Hernández-Avila, M., \& Lazcano-Ponce, E. (2009). Screen time and adiposity in adolescents in Mexico. Public Health Nutr, 12, 1938-1945. http://dx.doi.org/10.1017/S1368980009004881

Lawman, H., \& Wilson, D. K. (2012). A review of family and environmental correlates of health behaviors in high-risk youth. Obes, 20(6), 1142-1157. http://dx.doi.org/10.1038/oby.2011.376

Lissner, L., Mehlig, K., Sjöberg, A., Chaplin, J., Niklasson, A., \& Albertsson-Wikland, K. (2013). Secular trends in weight, height and BMI in young Swedes: The 'Grow up Gothenburg' studies. Acta Pediatr, 102(3), 314-317. http://dx.doi.org/10.1111/apa.12087

Lissner, L., Sohlström, A., Sundblom, E., \& Sjoberg, A. (2010). Trends in overweight and obesity in Swedish schoolchildren 1999-2005: Has the epidemic reached a plateau? Obes Rev, 11, 553-559. http://dx.doi.org/10. 1111/j.1467-789X.2009.00696.x

Marsh, S., Ni Mhurchu, C., Jiang, Y., \& Maddison, R. (2014). Comparative effects of TV watching, recreational computer use, and sedentary video game play on spontaneous energy intake in male children. A randomised crossover trial. Appetite, 77, 13-18. http://dx.doi.org/10.1016/j.appet.2014.02.008

McVeigh, J., \& Meiring, R. (2014). Physical activity and sedentary behavior in an ethnically diverse group of South African school children. J Sports Sci Med, 13(2), 371-8.

Moore, J. B., Jilcott, S. B., Shores, K. A., Evenson, K. R., Brownson, R. C., \& Novick, L. F. (2010). A qualitative examination of perceived barriers and facilitators of physical activity for urban and rural youth. Health Educ Res, 25(2), 335-367. http://dx.doi.org/10.1093/her/cyq004

Muthuri, S. K., Wachira, L. J., Onywera, V. O., \& Tremblay, M. S. (2014). Correlates of objectively measured overweight/obesity and physical activity in Kenyan schoolchildren: Results from ISCOLE-Kenya. BMC Public Health, 14, 436. http://dx.doi.org/10.1186/1471-2458-14-436

Olaya Contreras, P., Bastidas, M., \& Arvidsson, D. (2014). Colombian Children with Overweight and Obesity Need Additional Motivational Support at School to Perform Health-Enhancing Physical Activity. J Phys Act Health, 12(5), 604-609. http://dx.doi.org/10.1123/jpah.2014-0024

Peltzer, K. (2010). Leisure time physical activity and sedentary behavior and substance use among in-school adolescents in eight African countries. Int J Behav Med, 17(4), 271-8. http://dx.doi.org/10.1007/s12529 $-009-9073-1$

Persson, S., Bente Hansen, B., Sørensen, T. I. A., Jennifer, L., \& Baker, J. L. (2010). Weight trends in Copenhagen schoolchildren from 2002 to 2007. Acta Pediatr, 99, 1675-1678.

Ravens-Sieberer, U., Auquier, P., \& Erhart, M. (2007). The KIDSCREEN-27 quality of life measure for children and adolescents: Psychometric results from a cross-cultural survey in 13 European countries. Qual Life Res, 16(8), 1347-1356. http://dx.doi.org/10.1007/s11136-007-9240-2

Salazar Jaramillo, A., Valencia Correa, M., Monsalve, D., Uribe Correa, A., \& Meíja Franco, F. (2010). Perfil alimentario y nutricional de Medellín. Retrieved May 9, 2014, from http://www.medellin.gov.co/irj/go/km/ docs/wpccontent/Sites/Subportal\%20del\%20Ciudadano/Bienestar\%20Social/Secciones/Indicadores\%20y\% 20Estad\%C3\%ADsticas/Documentos/2011/perfil\%202010.pdf

Saunders, T. J., Chaput, J. P., \& Tremblay, M. S. (2014). Sedentary Behaviour as an Emerging Risk Factor for Cardiometabolic Diseases in Children and Adolescents. Can J Diabetes, 38(1), 53-61. http://dx.doi.org/10. 1016/j.jcjd.2013.08.266

Smith, J., Grunseit, A., Hardy, L., King, L., Wolfenden, L., \& Milat, A. (2010). Parental influences on child physical activity and screen viewing time: A population based study. BMC Public Health, 10, 593. http://dx.doi.org/10.1186/1471-2458-10-593

Vélez, C., \& Garcia, H. (2012). Medición de la calidad de vida en niños. Iatreia, 25(3), 240-249.

Vinther-Larsen, M., Riegels, M., Rod, M. H., Schøtz, M., Curtis, T., \& Grønbaek, M. (2010).The Danish Youth Cohort: characteristics of participants and non-participants and determinants of attrition. Scand J Public Health, 38(6), 648-656. http://dx.doi.org/10.1177/1403494810374222

Whitt-Glover, M. C., Taylor, W. C., Floyd, M. F., Yore, M. M., Yancey, A. K., \& Matthews, C. E. (2009). Disparities in physical activity and sedentary behaviors among US children and adolescents: Prevalence, correlates, and intervention implications. J Public Health Policy, 30(1), 309-334. http://dx.doi.org/ 10.1057/jphp.2008.46 
World Health Organization. (2010). Global recommendations on physical activity for health. WHO, Geneva.

World Health Organization. (2014). Global Strategy on Diet, Physical Activity and Health: Childhood overweight and obesity. WHO, Geneva.

\section{Copyrights}

Copyright for this article is retained by the author(s), with first publication rights granted to the journal.

This is an open-access article distributed under the terms and conditions of the Creative Commons Attribution license (http://creativecommons.org/licenses/by/3.0/). 